\title{
Prevalence and covariates of food insecurity among residents of single-room occupancy housing in Chicago, IL, USA
}

\author{
Elizabeth A Bowen 1 * , Sarah K Bowen ${ }^{2}$ and Anamika Barman-Adhikari ${ }^{3}$ \\ ${ }^{1}$ School of Social Work, University at Buffalo, State University of New York, 685 Baldy Hall, Buffalo, NY 14260, \\ USA: ${ }^{2}$ Department of Sociology and Anthropology, North Carolina State University, Raleigh, NC, USA: \\ ${ }^{3}$ Graduate School of Social Work, University of Denver, Denver, CO, USA
}

Final revision received 2 March 2015: Final revision received 30 June 2015: Accepted 8 July 2015: First published online 17 August 2015

\begin{abstract}
Objective: Emerging evidence suggests that food insecurity is a significant public health concern among people who are homeless or marginally housed. The present study assessed prevalence of food insecurity and its covariates among a group of marginally housed individuals living in single-room occupancy (SRO) dwellings, a population for which there is little extant health or nutrition research. Design: Cross-sectional survey incorporating the Household Food Insecurity Access Scale.

Setting: Ten private SRO residences in the Uptown neighbourhood of Chicago, IL, USA, 2013.

Subjects: SRO residents over 18 years of age who were able to communicate verbally in English ( $n$ 153).

Results: Food insecurity was widespread among SRO residents, with $75 \%$ of the sample considered food insecure and 52\% meeting criteria for severe food insecurity. Bivariate analyses indicated that female gender, eating most meals at a soup kitchen, having a mental health condition, problem drinking, having at least one chronic health condition, and diabetes were all significantly associated with food insecurity. In the multivariate ordered logistic regression model, eating most meals at a soup kitchen remained as the only significant correlate of food insecurity $(\mathrm{OR}=10 \cdot 13)$.

Conclusions: SRO residents and other marginally housed populations face unique food access challenges. Although targeted assistance in the form of food stamps and congregate meal programmes remains critical, efforts to prevent and address food insecurity among homeless and marginally housed individuals should include policy interventions that recognize poverty as the root cause of food insecurity and aim to increase overall income and improve housing conditions.
\end{abstract}

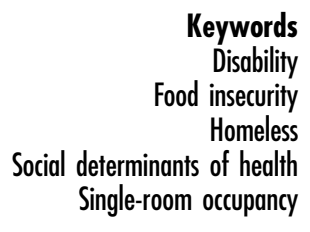

In 2013, one out of seven American households experienced food insecurity, meaning that they did not have enough food for a healthy, active lifestyle for all family members ${ }^{(1)}$. In the USA, food insecurity rates are higher among families with children and single parent-headed households, in Black and Hispanic households, and among people with psychiatric or physical disabilities ${ }^{(2-4)}$. Research indicates that food insecurity is also influenced by aspects of place and the built environment, including area (e.g. urban compared with rural) and neighbourhood characteristics $^{(5,6)}$. For example, studies have linked food security in urban settings with neighbourhood attributes such as walkability and ease of access to outlets selling fresh fruits and vegetables ${ }^{(7,8)}$. A recent review on place and food insecurity ${ }^{(5)}$ noted that more research is needed on this topic, particularly to better understand interactions between neighbourhood-level variables, including the socio-economic status of neighbourhoods, and householdlevel variables such as poverty, family composition and housing arrangements.

Although housing is an important aspect of the built environment and is often conceptualized as a social determinant of health, relatively few studies have examined food insecurity in the context of housing instability and homelessness in high-resource countries such as the USA and Canada. Among low-income urban households in these countries, food insecurity may be associated with unstable and vulnerable housing situations, such as living in shelters, in 'doubled up' or overcrowded housing scenarios, or in single-room occupancy (SRO) dwellings ${ }^{(9-11)}$. 
Food insecurity has been associated with homelessness in general samples of low-income households ${ }^{(12)}$ as well as in studies of specific demographic groups, including families headed by single mothers ${ }^{(13)}$ and street youth ${ }^{(14,15)}$.

Other studies have found high rates of food insecurity among homeless or unstably housed individuals with co-occurring health or mental health conditions such as HIV/ AIDS, diabetes and psychiatric impairments ${ }^{(9,16-20)}$. These studies have generally found that food insecurity is associated with worse health outcomes and greater drug and sex-related risk behaviours for people with these conditions. In addition, research has indicated that food insecurity, exposure to violence, and housing instability and homelessness are often interlinked, particularly for women ${ }^{(21-23)}$.

Individuals who are not literally homeless, but who are living in SRO buildings or in otherwise marginal housing situations, may face particular challenges related to food access. SRO dwellings are hotel or apartment buildings where individuals can rent small dormitory-style rooms (usually under $18 \mathrm{~m}^{2}$ ) on a daily, weekly or monthly basis. Bathrooms are typically shared and SRO rooms do not have in-unit kitchens or cooking facilities, distinguishing them from efficiency or studio apartments. Although many SRO buildings have been demolished or converted into other types of housing in recent years, they continue to be an important source of affordable housing for low-income single adults in many US and Canadian cities ${ }^{(24-26)}$. SRO residents' meal options are limited, in that their living spaces do not include a stove or food preparation space, and they may or may not have access to food storage and preparation equipment such as a small refrigerator or microwave. Although few studies have examined the context and prevalence of food insecurity for SRO residents specifically, previous research has noted the challenges of food preparation even in comparatively spacious extended-stay hotel housing where rooms include a kitchenette ${ }^{(27)}$.

Given the paucity of research on this issue, the present study assessed the prevalence and dimensions of food insecurity among a sample of residents living in SRO housing in Chicago, IL, USA. Study participants were recruited from privately owned SRO buildings in Uptown, a racially and economically diverse neighbourhood on Chicago's North Side. Uptown is noted for its historic concentration of SRO buildings, shelters, social service agencies and community organizations, including food pantries and soup kitchens ${ }^{(28)}$.

The study hypothesized that a range of social and health-related variables, as well as demographic factors, would be related to food insecurity in the SRO population. Our selection of covariates was informed by the available literature on food insecurity among homeless and marginally housed populations as well as a social and environmental determinants of health perspective ${ }^{(6)}$. This theoretical framework specifies that in addition to proximal biomedical influences, a range of sociopolitical, economic and geographic factors serve as 'upstream' determinants of health and disease ${ }^{(29)}$. Within a social determinants of health framework, the literature on food insecurity has positioned this issue as both an intermediary condition that influences a number of other health conditions and health behaviours, and a discrete health outcome that is shaped by social, economic and healthrelated factors ${ }^{(5,7,18,19,30-33)}$.

Drawing from this literature, we selected social-financial, health-risk and demographic covariates for our analysis. Social-financial covariates included education, income, access to Supplemental Nutrition Assistance Program (SNAP) benefits and housing subsidies, utilization of free meal sites (e.g. soup kitchens and churches) and recent street homelessness or incarceration. In an effort to accurately assess participants' financial resources, income was measured including both 'legitimate' (e.g. disability benefits, wages) and under-the-table sources such as informal employment and illicitly earned income ${ }^{(34)}$. Health-risk covariates included presence of chronic physical and mental health conditions, recent substance use (problem drinking and illicit drug use) and trading sex for money. Demographic covariates (age, race and gender) were also assessed.

\section{Methods}

\section{Sampling and data collection}

Food insecurity data were collected as part of a research project on the health, housing context and HIV-risk behaviour of SRO residents in Chicago's Uptown neighbourhood. In consultation with local community organizations, ten privately owned, for-profit SRO buildings were identified in Uptown in the spring of 2013. Participants were recruited primarily (90\%) through face-to-face recruitment in public areas of these buildings, such as the main lobby. In-person recruitment was supplemented by the use of fliers; several participants also called about the study after hearing about it from a friend or neighbour. At one SRO building, participants completed the study's eligibility screening and survey interview on site in a private conference room. At the other SRO buildings no space was available to complete the study procedures, so participants completed the study at the Uptown satellite office of a nearby community-based social service organization.

Eligibility criteria included being at least 18 years old, currently living (defined as having spent at least the previous night) in one of the SRO buildings in the sampling frame, and demonstrated ability to communicate verbally in English and provide informed consent. The study's principal investigator conducted the majority of the eligibility screenings and survey interviews (90\%), with the remainder conducted by a trained master's-level research assistant. Participants received \$US 20 in cash as compensation, as well as information about local health, housing and social service resources. The study procedures were approved by the Institutional Review Board at the principal investigator's university. 


\section{Measures}

Participants completed an interviewer-administered survey that contained items from several other established survey instruments as well as original questions. Main variables for the current analysis included food insecurity as measured by the Household Food Insecurity Access Scale (HFIAS) ${ }^{(35)}$ and demographic, social-financial and health-risk covariates. Prior to its use, the survey was pilottested and refined with a small sample of SRO residents.

\section{Food insecurity}

Food insecurity was assessed by the HFIAS, a nine-item scale developed by the Food and Nutrition Technical Assistance Project of the US Agency for International Development and used in numerous countries to capture the severity and key dimensions of food insecurity ${ }^{(18,20,35)}$. Research conducted in Canada indicates that the HFIAS is an appropriate measure of food insecurity among North American homeless populations, as this measure was preferred by homeless respondents to other instruments ${ }^{(36)}$. Scores on the HFIAS range from 0 to 27 , depending on the frequency (never, rarely, sometimes or often) with which the respondent answers questions such as 'Did you have to eat fewer meals in a day because there was not enough food?'

Questions on the original HFIAS are phrased in terms of households but were modified to refer to a single individual for the current study, since all of the participants lived by themselves. The recall period was also modified slightly, from 4 weeks on the HFIAS to $30 \mathrm{~d}$, in order to be consistent with the recall periods for other items on the study's survey interview. Higher HFIAS scores reflect greater food insecurity. The instrument also provides scoring guidelines, based on both total score and responses to particular items, which classify individuals into one of four categories: food secure, mildly food insecure, moderately food insecure and severely food insecure ${ }^{(35)}$.

\section{Covariates}

Demographic, social-financial and health-risk covariates were captured by the survey. The race variable consisted of three categories: African American, White and other race/more than one race, coded as 0,1 and 2, respectively. Gender was a dichotomous variable, with males coded as 0 . Age was a continuous variable. Education was measured as a three-level categorical variable: did not graduate high school; earned high school diploma or GED (General Educational Development); and some college/college degree. Two continuous measures of past-month income were assessed. A 'legitimate' measure included income only from official sources such as formal employment and Social Security retirement or disability benefits (Social Security Disability Income (SSDI) or Supplemental Security Income (SSI)). A 'comprehensive' measure included official as well as under-the-table sources (e.g. informal employment such as window washing or babysitting and illicit sources such as drug sales). Social-financial covariates also included the following dichotomous indicators: receipt of a rental subsidy in the past month; receipt of SNAP benefits in the past month; homelessness in the past year, defined as sleeping in an emergency shelter or in places not meant for human habitation; incarceration in a jail or prison in the past year; and reliance on soup kitchens, churches or other free meal sites for most meals, compared with participants who reported eating most meals in their SRO rooms or common areas, at friends' or family members' homes, or in fast-food places and other restaurants.

Health-risk covariates included the following dichotomous indicators: self-report of a serious mental health condition; self-report of at least one chronic health condition and of HIV/AIDS and diabetes specifically; problem drinking; illicit drug use other than marijuana in the past month; and trading sex for money, drugs or shelter in the past month. Self-report of a mental health condition was assessed by participants' response to the question 'Have you ever been told by a doctor, psychologist, social worker, or other health professional that you have a serious mental illness or mental health condition?' Participants who responded affirmatively were asked if the condition was depression, bipolar disorder, schizophrenia or another disorder. This question was adapted from a needs assessment of homeless persons in the Chicago area ${ }^{(37)}$. Participants were asked about having thirteen types of chronic medical conditions, using categories adapted from the US national Health Care for the Homeless Users Survey $^{(38)}$ : asthma, chronic obstructive pulmonary disease, tuberculosis, HIV/AIDS, diabetes, hypertension, stroke, heart disease, cancer, kidney disease, hepatitis $\mathrm{C}$, other liver disease and arthritis. In addition to calculating the number of participants who reported having at least one of these chronic conditions, self-report of HIV/AIDS diagnosis or diabetes diagnosis was included separately in the bivariate analysis, due to the frequently noted association of these conditions with food insecurity in other research ${ }^{(17,18,20)}$. Problem drinking was indicated by having a score of 3 or more on the FAST assessment ${ }^{(39)}$, which is a shorter version of the AUDIT screening. Illicit drug use and sex exchange were measured using items adapted from the Risk Behavior Assessment ${ }^{(40)}$.

\section{Statistical analyses}

Statistical analyses were conducted using the statistical software package Stata version 11.2. Cronbach's $\alpha$ was assessed as a measure of internal consistency for the HFIAS. HFIAS scoring guidelines were used to classify participants into one of four established categories: food secure, mildly food insecure, moderately food insecure or severely food insecure, with the mild and moderate categories combined for the analyses. Proportions and means were calculated for the demographic, social-financial and health-risk covariates for the sample as a whole and for the 
mild/moderate and severely food insecure categories. Bivariate ordered logistic regressions were conducted between all covariates and a three-level dependent variable, which consisted of the HFIAS designations of food secure, mildly/moderately food insecure and severely food insecure. A likelihood ratio test was conducted after each regression to ensure that the proportional odds assumption was not violated. All covariates that were statistically significant or approached significance at $P<0 \cdot 10$ in the bivariate analysis were included as predictors in a final multivariate ordered logistic regression model using the same dependent variable ${ }^{(41)}$.

\section{Results}

Of the 224 SRO residents recruited, 176 (79\%) showed for appointments to complete the study procedures. After screening for eligibility and post-interview quality control procedures, 163 cases were retained for analysis. One of the SRO buildings in the sampling frame had an on-site cafeteria at which participants could choose to eat one to three daily meals, for an additional cost added to their monthly rent. Since this impacted participants' food access in ways that may not generalize to the majority of SRO buildings that do not have cafeterias, participants who reported eating more than one meal per day in the cafeteria were excluded from the analyses. The final number for analysis was 153 , with one fewer case for some analyses due to missing data.

Table 1 summarizes food insecurity rates and key covariates for the sample. Participants' HFIAS scores ranged from 0 to 24, with a mean of $7 \cdot 6$ (SD 7·1). Cronbach's $\alpha$ was $0 \cdot 90$, indicating strong internal consistency for the scale. Food insecurity was common, with only $25 \%$ of participants classified as food secure and the remainder considered mildly (3\%), moderately (20\%) or severely (52\%) food insecure. Due to the low number of participants in the mild group, the categories of mildly and moderately food insecure were collapsed for the analyses. As per HFIAS scoring guidelines, only participants with scores of 0 or 1 were categorized in the food secure group. Total HFIAS scores averaged 4.5 (SD 2.7) for the combined mild/moderately food insecure category and $12 \cdot 7$ (SD 6.1) for the severely food insecure group.

The sample was predominantly African American (64\%) and male (80\%). Monthly income ranged from \$US 0 (for participants who had no income and received full rental subsidies that allowed them to live in SRO housing) to \$US 5800. To truncate the range, outliers above \$US 2000 were

Table 1 Description of the study sample of SRO residents in Chicago, IL, USA, 2013: overall sample and by HFIAS category

\begin{tabular}{|c|c|c|c|c|}
\hline & $\begin{array}{c}\text { Total study } \\
\text { participants ( } n \text { 153) }\end{array}$ & $\begin{array}{c}\text { Food secure } \\
\text { participants }(n 38)\end{array}$ & $\begin{array}{l}\text { Mildly/moderately food insecure } \\
\text { participants }(n 36)\end{array}$ & $\begin{array}{l}\text { Severely food insecure } \\
\text { participants }(n 79)\end{array}$ \\
\hline Total HFIAS score (mean) & $7 \cdot 6$ & 0.03 & 4.5 & $12 \cdot 7$ \\
\hline \multicolumn{5}{|l|}{ Race (\%) } \\
\hline African American & 64 & 58 & 69 & 65 \\
\hline White & 26 & 34 & 19 & 24 \\
\hline Other race/more than one race & 10 & 8 & 11 & 11 \\
\hline Female (\%) & 20 & 8 & 19 & 25 \\
\hline Age (years; mean) & $49 \cdot 8$ & $53 \cdot 3$ & $48 \cdot 0$ & $48 \cdot 9$ \\
\hline \multicolumn{5}{|l|}{ Education (\%) } \\
\hline Did not graduate high school & 25 & 18 & 25 & 28 \\
\hline High-school diploma or GED & 35 & 34 & 33 & 37 \\
\hline Some college or college degree & 40 & 48 & 42 & 35 \\
\hline $\begin{array}{l}\text { Monthly income from legitimate } \\
\text { sources (\$US; mean) }\end{array}$ & 705 & 806 & 714 & 651 \\
\hline $\begin{array}{l}\text { Monthly income from all sources } \\
\text { (\$US; mean) }\end{array}$ & 812 & 949 & 803 & 750 \\
\hline Receive a housing subsidy (\%) & 33 & 34 & 39 & 30 \\
\hline $\begin{array}{l}\text { Receive SNAP benefits in past } \\
\text { month (\%) }\end{array}$ & 73 & 66 & 75 & 76 \\
\hline $\begin{array}{l}\text { Eat most meals at soup kitchen or } \\
\text { church (\%) }\end{array}$ & 17 & 3 & 6 & 29 \\
\hline Homeless in past year (\%) & 18 & 18 & 11 & 22 \\
\hline Incarcerated in past year (\%) & 15 & 18 & 11 & 15 \\
\hline Mental health condition (\%) & 65 & 50 & 61 & 75 \\
\hline Problem drinking (\%) & 35 & 29 & 25 & 42 \\
\hline Illicit drug use in past $30 \mathrm{~d}(\%)$ & 17 & 11 & 14 & 22 \\
\hline Sex trade in past $30 \mathrm{~d}(\%)$ & 4 & 0 & 0 & 8 \\
\hline $\begin{array}{l}\text { One or more chronic health } \\
\text { conditions (\%) }\end{array}$ & 82 & 76 & 72 & 90 \\
\hline HIV & 6 & 3 & 6 & 8 \\
\hline Diabetes & 14 & 5 & 11 & 19 \\
\hline
\end{tabular}

SRO, single-room occupancy; HFIAS, Household Food Insecurity Access Scale; GED, General Educational Development; SNAP, Supplemental Nutrition Assistance Program. 
recoded to this level; this affected one score on the legitimate income measure and three scores on the comprehensive income measure. Participants' income came from a variety of sources, including SSI/SSDI (reported by $66 \%$ of the sample), formal employment (14\%), retirement benefits (5\%), and under-the-table employment and illicit sources (44\%). Total monthly income from legitimate sources averaged \$US 705 (SD \$US 415 ) and increased to \$US 812 (SD \$US 410) when income from under-the-table or illicit sources was included. The average monthly SNAP benefit amount for participants who reported receiving this benefit was \$US 133 (SD \$US 76). Almost one in five participants reported eating most of their meals at a soup kitchen or church. Both serious mental illness and chronic health conditions, including arthritis, hypertension, heart disease/stroke and diabetes, were frequently reported by participants. Participants also reported engaging in risk behaviours such as problem drinking (35\%) and illicit drug use (17\%) in the past $30 \mathrm{~d}$; a minority reported exchanging sex for money (4\%).

The results of the bivariate ordered logistic regressions are shown in Table 2. Odds ratios in ordered (also called ordinal) logistic regression can be interpreted as the odds of one level of an ordinal dependent variable occurring in comparison to the other levels of the variable, given a one-unit increase in the predictor variable ${ }^{(42)}$. In this analysis, an odds ratio greater than 1 indicates increased

Table 2 Bivariate ordered logistic regression analysis of mild/ moderate or severe food insecurity status and demographic, social-financial and health-risk covariates among a sample of SRO residents in Chicago, IL, USA, 2013 ( $n$ 153)

\begin{tabular}{|c|c|c|c|}
\hline & OR & $95 \% \mathrm{Cl}$ & $P$ value \\
\hline \multicolumn{4}{|l|}{ Demographic } \\
\hline \multicolumn{4}{|l|}{ Race } \\
\hline African American & & Ref. & - \\
\hline White & 0.75 & $0.37,1.52$ & 0.43 \\
\hline Other & $1 \cdot 20$ & $0.43,3.30$ & 0.73 \\
\hline Female & $2 \cdot 37$ & $1 \cdot 05,5 \cdot 34$ & 0.04 \\
\hline Age & 0.98 & $0.95,1.01$ & 0.12 \\
\hline \multicolumn{4}{|l|}{ Social-financial } \\
\hline \multicolumn{4}{|l|}{ Education } \\
\hline Did not graduate high school & & Ref. & - \\
\hline High-school diploma or GED & 0.81 & $0.36,1.80$ & 0.60 \\
\hline Some college or college degree & 0.60 & $0.27,1.29$ & 0.19 \\
\hline $\begin{array}{l}\text { Monthly income from legitimate } \\
\text { sources, \$US } 100 \text { increments }\end{array}$ & 0.93 & $0.87,1.00$ & 0.07 \\
\hline $\begin{array}{l}\text { Monthly income from all sources, } \\
\text { \$US } 100 \text { increments }\end{array}$ & 0.91 & $0.85,0.99$ & 0.02 \\
\hline Housing subsidy & 0.82 & $0.44,1.54$ & 0.54 \\
\hline SNAP benefits in past month & 1.43 & $0.73,2 \cdot 82$ & 0.30 \\
\hline $\begin{array}{l}\text { Eat most meals at soup } \\
\text { kitchen or church }\end{array}$ & $9 \cdot 75$ & $2 \cdot 80,34 \cdot 01$ & $<0.01$ \\
\hline Homeless in past year & $1 \cdot 38$ & $0.61,3.11$ & 0.44 \\
\hline Incarcerated in past year & 0.90 & $0.38,2.12$ & 0.82 \\
\hline \multicolumn{4}{|l|}{ Health-risk } \\
\hline Mental health condition & $2 \cdot 38$ & $1 \cdot 26,4 \cdot 48$ & $<0.01$ \\
\hline Problem drinking & 1.77 & $0.92,3.42$ & 0.09 \\
\hline Illicit drug use in past $30 \mathrm{~d}$ & 2.02 & $0.86,4.75$ & 0.11 \\
\hline Sex trade in past $30 \mathrm{~d}$ & \multicolumn{2}{|c|}{ Perfect predictor } & - \\
\hline $\begin{array}{l}\text { One or more chronic health } \\
\text { conditions }\end{array}$ & $2 \cdot 29$ & $1.08,4.87$ & 0.03 \\
\hline HIV & 2.06 & $0.52,8.23$ & 0.31 \\
\hline Diabetes & 2.77 & $1.03,7.44$ & 0.04 \\
\hline
\end{tabular}

SRO, single-room occupancy; GED, General Educational Development; SNAP, Supplemental Nutrition Assistance Program; Ref., referent category. likelihood of being in the severely food insecure group ('level 3' of the dependent variable), compared with the mild/moderately food insecure or food secure group (levels 2 and 1, respectively); or of being in the severely food insecure or mild/moderately insecure group (levels 3 and 2), in comparison with the food secure group (level 1).

Our bivariate analyses indicated that female gender, eating most meals at a soup kitchen or church, having a mental health condition, problem drinking, having at least one chronic health condition, and diabetes were all significantly associated with increased odds of mild/ moderate or severe food insecurity. Both measures of income were significantly negatively associated with food insecurity. For example, a \$US 100 increase in total income was associated with a $9 \%$ reduction in the odds of being classified in the mild/moderately or severely food insecure group. All of the participants reporting sex exchange in the past $30 \mathrm{~d}(n$ 6) were classified as severely food insecure; this variable was therefore considered a 'perfect predictor' and could not be accurately modelled.

Variables that demonstrated significant associations with food insecurity at the level of $P<0.10$ in the bivariate analysis were included in a multivariate ordered logistic regression model (Table 3). To accurately reflect participants' financial resources, the comprehensive measure of income was selected for the multivariate analyses. The overall model was statistically significant (likelihood ratio $\left.\chi^{2}=38 \cdot 21, P<0 \cdot 01\right)$ and McFadden's pseudo $R^{2}$ was $0 \cdot 12$, generally indicative of a small-to-medium effect size ${ }^{(43)}$. Only one covariate, eating most meals at a soup kitchen or church, remained significant at the $P<0.05$ level in the multivariate model. Specifically, people who reported eating most of their meals at a soup kitchen or church were ten times more likely to be in one of the two food insecure categories. Four other variables - female gender, income, having a mental health condition and having diabetes - trended towards significance (i.e. $P<0 \cdot 10$ ).

Table 3 Multivariate ordered logistic regression analysis of mild/ moderate or severe food insecurity status and selected demographic, social-financial and health-risk covariates among a sample of SRO residents in Chicago, IL, USA, 2013 ( $n$ 153)

\begin{tabular}{|c|c|c|c|}
\hline & OR & $95 \% \mathrm{Cl}$ & $P$ value \\
\hline \multicolumn{4}{|l|}{ Demographic } \\
\hline Female & $2 \cdot 18$ & $0.90,5 \cdot 26$ & 0.08 \\
\hline \multicolumn{4}{|l|}{ Social-financial } \\
\hline $\begin{array}{l}\text { Monthly income from all } \\
\text { sources, \$US } 100 \\
\text { increments }\end{array}$ & 0.93 & $0.86,1.01$ & 0.07 \\
\hline $\begin{array}{l}\text { Eat most meals at soup } \\
\text { kitchen or church }\end{array}$ & $10 \cdot 13$ & $2 \cdot 76,37 \cdot 14$ & $<0.01$ \\
\hline \multicolumn{4}{|l|}{ Health-risk } \\
\hline Mental health condition & 1.87 & $0.93,3.75$ & 0.08 \\
\hline Problem drinking & 1.57 & $0.77,3.18$ & 0.21 \\
\hline $\begin{array}{l}\text { One or more chronic health } \\
\text { conditions }\end{array}$ & 1.04 & $0.43,2.50$ & 0.93 \\
\hline Diabetes & 2.56 & $0.89,7.39$ & 0.08 \\
\hline
\end{tabular}

SRO, single-room occupancy. 
Although this is not the threshold for a priori significance, given the small sample size, we believe that these associations might be important in identifying potential risk and protective factors related to levels of food insecurity for SRO residents. Specifically, total income was associated with a lower risk of food insecurity (OR $=0.93, P=0.07)$. Women (OR $=2 \cdot 18, P=0 \cdot 08)$, people who reported having a mental health condition $(\mathrm{OR}=1 \cdot 87, P=0.08)$ and diabetics ( $\mathrm{OR}=2.56, P=0.08)$ were more likely to be classified as mild/moderately or severely food insecure.

\section{Discussion}

Using the well-established HFIAS measure, the results of the present study indicate an alarming level of food insecurity among residents of SRO housing. Three-quarters of study participants were classified as food insecure. This prevalence is comparable to Holland and colleagues' study ${ }^{(36)}$, which reported a $70 \%$ rate of food insecurity among a sample of fifty homeless individuals in Toronto using the HFIAS, although it is somewhat higher than Weiser et al.'s study ${ }^{(20)}$ of homeless and marginally housed HIV-positive San Francisco residents, which noted a food insecurity rate of $54 \%$. A larger study using a representative sample of low-income families in the USA reported a food insecurity rate of $77 \%$ among families experiencing housing instability, although this was based on a three-item measure rather than a more comprehensive scale such as the HFIAS ${ }^{(44)}$. The high prevalence of severe food insecurity, found among $52 \%$ of participants in our study, is also striking and exceeds rates reported in previous research such as Holland et al. (42\%) and Weiser et al. (32\%). Although we cannot make a direct comparison between our HFIAS-based results and food insecurity rates in the US general population as determined by the US Department of Agriculture's Household Food Security Survey Module, our results suggest that the prevalence of food insecurity among SRO residents far exceeds the $14 \%$ prevalence noted in the population as a whole ${ }^{(1)}$.

Our study indicated a trend towards women being more likely to experience food insecurity. Depth of poverty may have been a contributing factor, as women in our sample had lower mean incomes than men (\$US $644 v$. \$US 720 on the legitimate income measure and \$US $701 v$. \$US 840 on the comprehensive measure). Limited prior research has also noted lower average incomes for women who are homeless or marginally housed, in comparison to their male counterparts ${ }^{(45)}$. Although we could not locate any studies linking depth of poverty and gender with food insecurity in marginally housed populations specifically, this dynamic is consistent with trends noted in the general population ${ }^{(46)}$.

Studies conducted among North American families have shown that food insecurity tends to be higher among women, who may make sacrifices to try to buffer children and other family members from experiencing food insecurity $^{(47-49)}$. It is difficult to know if this explanation applies to our finding, as SRO buildings house single adults and generally do not allow children to live on the premises. Nevertheless, it is possible that the women in the study may have maintained caregiving relationships with children or other family members living elsewhere, and that this could be tied to their increased risk of food insecurity. Further, women often constitute a minority in SRO buildings, as was the case in our study, and may face added vulnerabilities in terms of exposure to violence and in some cases harassment from male SRO tenants and management ${ }^{(50,51)}$. Additional research is needed to better understand how women's experiences in marginal housing environments may be linked to food insecurity.

While both measures of income were significantly negatively associated with food insecurity in the bivariate regression model, receiving SNAP benefits was not. Other researchers have noted that when samples are confined to low-income households, it is not uncommon to find no statistically significant effect of income on food insecurity $^{(13)}$. In this case, food insecurity may have been so extreme for some participants (e.g. $22 \%$ reported going a whole day and night without eating anything at least once in the past month) that even relatively minor differences in income appeared to impact participants' food access. The non-significant impact of receiving SNAP benefits on food insecurity may be a function of self-selection effects. Nationally in the USA, the prevalence of very low food insecurity is much higher among food stamp participant households than among low-income non-participant households; this is likely because households facing greater hardship are more likely to join the programme ${ }^{(52)}$. The lack of significance of SNAP as a covariate also likely reflects the high rate of SNAP participation in the present study ( $73 \%$ of the sample).

The finding that food insecurity remained high even among SNAP recipients may also be tied to SRO residents' severe limitations in terms of food storage and preparation. Anecdotally, several participants noted during the survey interviews that even when they could buy food or obtain food donations, their options were mostly limited to non-perishable items that did not require cooking or other extensive preparation - a bind that would clearly impact the scope of participants' dietary choices. A large body of research has examined the relationship between food insecurity and unhealthy eating patterns (e.g. eating fewer fruits and vegetables); there is support for the idea that food insecurity negatively affects diet quality, particularly among adults ${ }^{(53)}$. Although one of the strengths of the HFIAS is its greater attention to food quality (e.g. dietary diversity and preferences) compared with alternative measures of food insecurity, the HFIAS still focuses mainly on the quantity of food consumed. Thus, although the rate of food insecurity among SRO residents as measured by the HFIAS in the present study was high, this may still not fully reflect the challenges associated with the types of foods SRO residents are likely to consume, such as having 
to rely primarily on processed food or food that does not require cooking.

In bivariate and multivariate analyses, eating most meals at a soup kitchen or church was significantly associated with being classified in the mild/moderately or severely food insecure groups. We hypothesize that this is also due to selfselection; people who rely on free meal programmes for the majority of their meals are likely experiencing greater hardships. Although these services are a critical resource to the people who rely on them, these results also appear to reflect the inherent challenges of utilizing soup kitchens as one's primary food source. Accessing food at free meal sites requires a degree of finesse and knowledge, in terms of learning about and abiding by the hours, rules and regulations of different programmes ${ }^{(54)}$. Congregate meal programmes may also have difficulty addressing the unique dietary needs that some individuals have due to conditions such as diabetes. The results of the current research suggest that although some individuals have no choice but to rely on such programmes, free meal programmes are not able to mitigate the effects of food insecurity.

Recent policy developments and media attention have highlighted the role that urban 'food deserts' may play in perpetuating diet-related health issues. Food deserts are typically defined as neighbourhoods where residents do not have easy access to full-service grocery stores where fresh produce and other healthy food options are readily available ${ }^{(55,56)}$. The high level of food insecurity in the present study is notable in that the census tracts where the SRO buildings were located do not meet the criteria for food deserts as defined by the US Department of Agriculture $^{(57)}$. All of the SRO buildings in the sampling frame were located within $1.6 \mathrm{~km}$ (1 mile) of a full-service grocery store, and the Uptown neighbourhood is well served by public transit, including multiple bus lines and a subway train. We cannot rule out the possibility that some participants nevertheless faced barriers in grocery store access, as we did not measure this directly or account for it in our analyses. For example, participants' disabling conditions in some instances may have limited their access to grocery stores, even when their SRO housing was located in relative proximity. The results of this and other studies suggest that the relationship between the local food environment and dietary and health outcomes is far from straightforward, and that other social-material factors such as household finances, housing status and disability, in addition to proximity to markets, are critical in explaining levels of food insecurity ${ }^{(58-61)}$.

Altogether, the results of the current study suggest that high levels of food insecurity may persist among lowincome, marginally housed populations such as SRO residents, despite access to grocery stores, free meal programmes and SNAP benefits. Soup kitchens and SNAP assistance can help address hunger in the short term, but do not address poverty as the root cause of food insecurity. Poverty is of course a multifaceted condition, and the layering of poverty with related stressors - not only food insecurity and housing instability, but increased exposure to violence and limited access to health care for example ${ }^{(21,44)}$ - presents a persistent challenge in designing policies and programmes to improve the wellbeing of disadvantaged individuals and families. In particular in the present study, poverty among people with disabilities appears to be a critical underlying factor associated with food insecurity. The most common income source for participants was disability benefits (SSI/ SSDI), with an average benefit amount of \$US 729. The annual income of an individual relying on a benefit of this level alone would fall considerably below the US federal poverty line of \$US 11490 for 2013. Thus, even with targeted food assistance, it is perhaps not surprising that food insecurity would persist for individuals relying on such limited incomes to meet their needs.

Consequently, in addition to federal food benefits like SNAP and private food pantries and soup kitchens, the present study's findings suggest that food insecurity among SRO residents could be better addressed through policy interventions to increase overall income. Elevated income would expand individuals' purchasing power for food and other necessities, as well as their housing options. Efficiency apartments, for example, have higher rents than SRO buildings, but would improve individuals' meal options since they typically include a stove and refrigerator. Policy interventions to increase income among SRO residents and other marginally housed populations should include attention to disability benefit levels. Past research has noted both the high rates of food insecurity among individuals with disabling conditions and the inadequacy of US disability benefit levels in meeting food, housing and other essential costs ${ }^{(3,4,62)}$.

The current study has a number of limitations. Given its cross-sectional design, the study does not provide a basis for establishing prediction or inferring a causal relationship between the covariates and food insecurity. The covariates included in our study are far from exhaustive; for example, although other research has indicated that food insecurity may be linked to exposure to violence ${ }^{(21-23)}$, we did not measure this in our study. Another limitation is that our overall sample size was small, likely limiting the ability to detect significant relationships among the variables. Since the sample was obtained through non-probability methods, we cannot say with confidence if it represents all SRO residents or if results would generalize to other marginally housed populations in other cities. The demographics of our sample, in which African American men comprised the majority, may not reflect the demographics of SRO residents nationally. An additional limitation concerns precision of measurement; for example, we asked participants where they ate most of their meals but did not require participants to quantify this, potentially resulting in unmeasured variation regarding the covariate of eating 'most' of one's meals at a free meal site. 
Our findings yielded additional questions that could not be answered given our data and the quantitative nature of the study. Considering that SRO residents are not literally homeless but face unique constraints in food preparation and storage, further qualitative research should examine how these constraints impact food insecurity among SRO residents as well as the strategies that residents use to manage them. Additionally, our findings also highlight the need for a more in-depth understanding of how lowincome marginally housed individuals prioritize their food purchases especially in relation to other competing basic needs such as health care and transportation, as well as spending related to risky behaviours such as alcohol, tobacco and other drug use. Further research in these areas can help to bring attention to the problem of food insecurity among SRO residents as well as inform policy interventions for improving food security and health among this vulnerable and often overlooked population.

\section{Acknowledgements}

Acknowledgements: The authors would like to thank the study participants for sharing their experiences, Christopher G. Mitchell for his instrumental advice on the design and implementation of the study, Community Outreach Intervention Projects for their support with data collection and Sebastino Aviles for his assistance with participant recruitment and data collection. Financial support: This study was supported by funding from the University of Illinois at Chicago Graduate College and the Society for Social Work and Research. The funders had no role in the design, analysis or writing of this article. Conflict of interest: None. Authorship: E.A.B. conceived of the study, facilitated data collection processes and led the analyses and writing of the manuscript. S.K.B. reviewed the relevant literature and drafted the introduction and discussion sections. A.B.-A. drafted the results section and assisted in data analysis. All authors contributed to editing the manuscript. Ethics of buman subject participation: All study procedures were reviewed and approved by the Institutional Review Board at the University of Illinois at Chicago.

\section{References}

1. Coleman-Jensen A, Gregory D \& Singh A (2014) Household Food Security in the United States in 2013. Economic Research Report no. 173. http://www.ers.usda.gov/media/ 1565415/err173.pdf (accessed January 2015).

2. US Department of Agriculture, Economic Research Service (2015) Food security in the United States - key statistics \& graphics. http://www.ers.usda.gov/topics/food-nutritionassistance/food-security-in-the-us/key-statistics-graphics. aspx \#trends (accessed January 2015).

3. Coleman-Jensen A \& Nord M (2013) Food Insecurity among Households with Working-Age Adults with Disabilities. Economic Research Report no. 144. http://www.ers.usda. gov/publications/err-economic-research-report/err144.aspx (accessed January 2015)
4. Huang J, Guo B \& Kim Y (2010) Food insecurity and disability: do economic resources matter? Soc Sci Res 39, 111-124.

5. Carter MA, Dubois L \& Tremblay MS (2014) Place and food insecurity: a critical review and synthesis of the literature. Public Health Nutr 17, 94-112.

6. Friel S, Akerman M, Hancock T et al. (2011) Addressing the social and environmental determinants of urban health equity: evidence for action and a research agenda. J Urban Health 88, 860-874.

7. Chung W, Gallo W, Giunta N et al. (2012) Linking neighborhood characteristics to food insecurity in older adults: the role of perceived safety, social cohesion, and walkability. J Urban Health 89, 407-418.

8. Mayer V, Hillier A, Bachhuber M et al. (2014) Food insecurity, neighborhood food access, and food assistance in Philadelphia. J Urban Health 91, 1087-1091.

9. Anema A, Wood E, Weiser SD et al. (2010) Hunger and associated harms among injection drug users in an urban Canadian setting. Subst Abuse Treat Prev Policy 5, 1-7.

10. Cutts DB, Meyers AF, Black MM et al. (2011) US housing insecurity and the health of very young children. Am J Public Health 101, 1508-1514.

11. Kirkpatrick S \& Tarasuk V (2011) Housing circumstances are associated with household food access among low-income urban families. J Urban Health 88, 284-296.

12. Furness BW, Simon PA, Wold CM et al. (2004) Prevalence and predictors of food insecurity among low-income households in Los Angeles County. Public Health Nutr 7 , 791-794.

13. Gundersen C, Weinreb L, Wehler C et al. (2003) Homelessness and food insecurity. J Hous Econ 12, 250-272.

14. Dachner N \& Tarasuk V (2002) Homeless 'squeegee kids': food insecurity and daily survival. Soc Sci Med 54, 1039-1049.

15. Whitbeck LB, Chen X \& Johnson KD (2006) Food insecurity among homeless and runaway adolescents. Public Health Nutr 9, 47-52.

16. Baggett TP, Singer DE, Rao SR et al. (2011) Food insufficiency and health services utilization in a national sample of homeless adults. J Gen Intern Med 26, 627-634.

17. Vijayaraghavan M, Jacobs EA, Seligman H et al. (2011) The association between housing instability, food insecurity, and diabetes self-efficacy in low-income adults. J Health Care Poor Underserved 22, 1279-1291.

18. Vogenthaler NS, Kushel MB, Hadley C et al. (2013) Food insecurity and risky sexual behaviours among homeless and marginally housed HIV-infected individuals in San Francisco. AIDS Behav 17, 1688-1693.

19. Wang EA, Zhu GFA, Evans L et al. (2013) A pilot study examining food insecurity and HIV risk behaviours among individuals recently released from prison. AIDS Educ Prev 25, 112-123.

20. Weiser SD, Bangsberg DR, Kegeles S et al. (2009) Food insecurity among homeless and marginally housed individuals living with HIV/AIDS in San Francisco. AIDS Behav 13, 841-848.

21. Chilton MM, Rabinowich JR \& Woolf NH (2014) Very low food security in the USA is linked with exposure to violence. Public Health Nutr 17, 73-82.

22. Hernandez DC, Marshall A \& Mineo C (2014) Maternal depression mediates the association between intimate partner violence and food insecurity. $J$ Womens Health $\mathbf{2 3}$, 29-37.

23. Riley ED, Cohen J, Knight KR et al. (2014) Recent violence in a community-based sample of homeless and unstably housed women with high levels of psychiatric comorbidity. Am J Public Health 104, 657-663.

24. Evans L \& Strathdee SA (2006) A roof is not enough: unstable housing, vulnerability to HIV infection and the plight of the SRO. Int J Drug Policy 17, 115-117. 
25. Hwang SW, Aubry T, Palepu A et al. (2011) The health and housing in transition study: a longitudinal study of the health of homeless and vulnerably housed adults in three Canadian cities. Int J Public Health 56, 609-623.

26. Knight KR, Lopez AM, Comfort M et al. (2014) Single room occupancy (SRO) hotels as mental health risk environments among impoverished women: the intersection of policy, drug use, trauma, and urban space. Int J Drug Policy 2, 556-561.

27. Lewinson T (2010) Residents' coping strategies in an extended-stay hotel home. J Ethnogr Qual Res 4, 180-196.

28. Byrne J (2013) In Uptown, freshman alderman angers advocates for the needy. http://articles.chicagotribune.com/201303-09/news/ct-met-cappleman-uptown-homeless-20130309_ 1_uptown-neighborhood-james-cappleman-homeless-people (accessed February 2015).

29. Commission on Social Determinants of Health, World Health Organization (2007) A conceptual framework for action on the social determinants of health. http://www. who.int/social_determinants/resources/csdh_framework_ action_05_07.pdf (accessed April 2015).

30. Cook JT, Black M, Chilton M et al. (2013) Are food insecurity's health impacts underestimated in the US population? Marginal food security also predicts adverse health outcomes in young US children and mothers. Adv Nutr $\mathbf{4}$, 51-61.

31. Olabiyia OM \& McIntyre L (2014) Determinants of food insecurity in higher-income households in Canada. J Hunger Environ Nutr 9, 433-448.

32. Tarasuk V, Mitchell A, McLaren L et al. (2013) Chronic physical and mental health conditions among adults may increase vulnerability to household food insecurity. $J$ Nutr 143, 1785-1793.

33. Seligman HK, Laraia BA \& Kushel MB (2010) Food insecurity is associated with chronic disease among low-income NHANES participants. J Nutr 140, 304-310.

34. Ompad DC, Nandi V, Cerda M et al. (2012) Beyond income: material resources among drug users in economicallydisadvantaged New York City neighborhoods. Drug Alcohol Depend 120, 127-134.

35. Coates J, Swindale A \& Bilinsky P (2007) Household Food Insecurity Access Scale (HFIAS) for Measurement of Food Access: Indicator Guide (v. 3). Washington, DC: Food and Nutrition Technical Assistance Project, Academy for Educational Development.

36. Holland AC, Kennedy MC \& Hwang SW (2011) The assessment of food security in homeless individuals: a comparison of the Food Security Survey Module and the Household Food Insecurity Access Scale. Public Health Nutr 14, 2254-2259.

37. Survey Research Laboratory, University of Illinois at Chicago (2000) Client Survey for Study \#866: Needs Assessment of the Homeless in Metropolitan Chicago. Chicago, IL: University of Illinois at Chicago.

38. Zlotnick C \& Zerger S (2009) Survey findings on characteristics and health status of clients treated by the federally funded (US) health care for the homeless programs. Health Soc Care Community 17, 18-26.

39. Hodgson RC, Hodgson RJ, John B et al. (2003) Fast screening for alcohol misuse. Addict Behav 28, 1453-1463.

40. National Institute on Drug Abuse (1991) Risk Behavior Assessment. Rockville, MD: National Institute on Drug Abuse.

41. Hosmer DW Jr, Lemeshow S \& Sturdivant RX (2013) Applied Logistic Regression, 3rd ed. Hoboken, NJ: John Wiley \& Sons, Inc.

42. Orme JG \& Combs-Orme T (2009) Multiple Regression with Discrete Dependent Variables. New York: Oxford University Press.
43. Ferguson CJ (2009) An effect size primer: a guide for clinicians and researchers. Prof Psychol Res Pract 40, 532-538.

44. Kushel MB, Gupta R, Gee L et al. (2006) Housing instability and food insecurity as barriers to health care among lowincome Americans. J Gen Intern Med 21, 71-77.

45. Riley ED, Weiser SD, Sorensen JL et al. (2007) Housing patterns and correlates of homelessness differ by gender among individuals using San Francisco free food programs. $J$ Urban Health 84, 415-422.

46. RTI International (2014) Current and prospective scope of hunger and food security in America: a review of current research. http://www.rti.org/pubs/full_hunger_report_final_ 07-24-14.pdf (accessed June 2015).

47. Martin MA \& Lippert AM (2012) Feeding her children, but risking her health: the intersection of gender, household food insecurity and obesity. Soc Sci Med 74, 1754-1764.

48. McIntyre L, Glanville NT, Raine KD et al. (2003) Do lowincome lone mothers compromise their nutrition to feed their children? CMAJ 168, 686-691.

49. Olson CM (2005) Food insecurity in women: a recipe for unhealthy trade-offs. Top Clin Nutr 20, 321-328.

50. Knight KR, Lopez AM, Comfort M et al. (2014) Single room occupancy (SRO) hotels as mental health risk environments among impoverished women: the intersection of policy, drug use, trauma, and urban space. Int J Drug Policy 25, 556-561.

51. Lazarus L, Chettiar J, Deering K et al. (2011) Risky health environments: women sex workers' struggles to find safe, secure and non-exploitative housing in Canada's poorest postal code. Soc Sci Med 73, 1600-1607.

52. Wilde PE (2007) Measuring the effect of food stamps on food insecurity and hunger: research and policy considerations. J Nutr 137, 307-310.

53. Hanson KL \& Connor LM (2014) Food insecurity and dietary quality in US adults and children: a systematic review. $A m J$ Clin Nutr 100, 684-692.

54. Miewald C \& McCann E (2014) Foodscapes and the geographies of poverty: sustenance, strategy, and politics in an urban neighborhood. Antipode 46, 537-556.

55. Beaulac J, Kristjansson E \& Cummins S (2009) Asystematic review of food deserts, 1966-2007. Prev Chronic Dis 6, A105.

56. Hendrickson D, Smith C \& Eikenberry N (2006) Fruit and vegetable access in four low-income food deserts communities in Minnesota. Agric Hum Values 23, 371-383.

57. US Department of Agriculture, Economic Research Service (2013) Food access research atlas: documentation. http:// www.ers.usda.gov/data-products/food-access-research-atlas/ documentation.aspx (accessed January 2015).

58. Alkon AH, Block D, Moore K et al. (2013) Foodways of the urban poor. Geoforum 48, 126-135.

59. Kirkpatrick SI \& Tarasuk V (2010) Assessing the relevance of neighbourhood characteristics to the household food security of low-income Toronto families. Public Health Nutr 13, 1139-1148.

60. Wiig K \& Smith C (2009) The art of grocery shopping on a food stamp budget: factors influencing the food choices of low-income women as they try to make ends meet. Public Health Nutr 12, 1726-1734.

61. Brewer DP, Catlett CS, Porter KN et al. (2010) Physical limitations contribute to food insecurity and the food insecurity-obesity paradox in older adults at senior centers in Georgia. J Nutr Elder 29, 150-169.

62. Stapleton DC, O'Day BL, Livermore GA et al. (2006) Dismantling the poverty trap: disability policy for the twenty-first century. Milbank Q 84, 701-732. 